\title{
Kinetic Size Effect During Dissolution of a Synthetic $\gamma$-Alumina
}

\author{
By Frank Roelofs ${ }^{1, *}$, Wolfram Vogelsberger ${ }^{2}$, and Gerd Buntkowsky ${ }^{2}$ \\ ${ }^{1}$ Chemiewerk Bad Köstritz GmbH, Heinrichshall 2, D-07586 Bad Köstritz, Germany \\ 2 Institute for Physical Chemistry, Chemistry and Earth Science Faculty, Friedrich-Schiller- \\ University Jena, Helmholtzweg 4, D-07743 Jena, Germany
}

Dedicated to Prof. Dr. Hans-Heinrich Limbach on the occasion of his $65^{\text {th }}$ birthday

(Received April 7, 2008; accepted May 20, 2008)

\section{Dissolution / Alumina / Kinetic Size Effect}

The dissolution process of a technical, nanodispersed $\gamma$-alumina in water was studied at $25{ }^{\circ} \mathrm{C}$ in the $\mathrm{pH}$ range $3.0 \leq \mathrm{pH} \leq 11.5$. Thereby, especial attention was paid to the influence of supersaturation on the dissolution behaviour observed. In conclusion, we were able to verify a size effect during the dissolution process, in the whole $\mathrm{pH}$ range investigated. In addition, we observed that changing supersaturation under identical conditions, leads to a shift of the maximum in the concentration profiles both, in absolute value and in time, when the maximum occurs. X-ray powder diffraction analysis and nitrogen adsorption measurements were used to identify the solid material collected during selected dissolution experiments. As a result, the formation of the aluminium phase -bayerite/gibbsite- could be excluded as a possible reason for the observed dissolution behaviour. The rate constants of the dissolution process were evaluated using the model of Gibbs free energy of cluster formation, which considers size effect among other factors. As a result, we were able to prove that the observed maxima in the concentration profiles were due to a kinetic size effect, caused by the size of the primary particles of the starting material, surface tension, and supersaturation in the system.

\section{Introduction}

$\gamma$-alumina is used in a wide range of technical applications, predominantly as adsorbent material, and as a substrate for catalysts [1], respectively. The high number of applications requires extensive knowledge about its properties during fabrication, as well as in practical use. The application of nanostructured materi-

\footnotetext{
* Corresponding author. E-mail: f.roelofs@cwk-bk.de
} 
als has played a key role in modern material science necessitating special methods of handling [2].

Written scientific contributions regarding the dissolution processes of aluminum oxide are rare, and principally deal with the investigation in relation to a specific point of analysis. Various reports exist concerning the corrosion process of alumina (ceramics) at high pressures and temperatures [3, 4], for example, or have specifically explored the solubility behaviour as influenced by the addition of inorganic [5] or organic substances [6, 7]. However, it is the dissolution process of the aluminium hydroxide phases, that has been the primary focus of extensive scientific study [8-15]. The interface behaviour between aluminium oxide as well as aluminum hydroxide and water is also subject to several investigations [16-22]. Without a doubt, the running processes in relation to the interface water/oxide interface, have a great deal of influence on the dissolution process itself.

In recent work [23], we have been able to demonstrate that a particular dissolution behaviour can be observed by dissolving nanodispersed $\gamma$-alumina in water, under normal conditions. Therefore, the existence of a kinetic size effect could be predicted, which confirmed our interpretation of the dissolution behaviour as scientifically founded. This special behaviour is attributable to very small radii of aluminium oxide; however, it was not observed to be present during all experiments. These observations had already been reported in cases where titania nanoparticles [24] were dissolved; elevated titanium concentration had been determined. In both cases, the significant influence of supersaturation/available surface area and interfacial energy, respectively, had been discerned in relation to the existence of the size effect during the dissolution process.

Within our current work, we intend to present new experimental results that display a distinct dependency of the shape of dissolution curves, on $\mathrm{pH}$ and supersaturation/available surface area, respectively. X-ray powder diffraction and nitrogen adsorption measurements have allowed us to understand the influence of the new phase formation (bayerite) on the dissolution behaviour observed. The high number of aqueous aluminium species present in scientific literature [25-37], must be taken into consideration when evaluating thermodynamic solubility. As already demonstrated in previous works [23, 24, 38, 39], we are able to describe the different dissolution curves of metal oxides with one appropriate model. This model considers both thermodynamic and kinetic aspects, with especial reference to the fact that the colloidal dispersion has an elevated free energy in comparison to the bulk phase. Without any special adjustments of the theoretical model, it is possible to describe the dissolution profiles theoretically.

\section{Experimental}

\subsection{Sample material}

The technical aluminium oxide Aluminiumoxid $C$ (Aeroxide ${ }^{\circledR} A l u C$ ), produced by Degussa AG, Germany, was used for the dissolution experiments. The charac- 
terisation of the test material, as well as of the further powder samples, were established using X-ray (powder) diffraction (XRD) and nitrogen adsorption measurements. Aeroxide Alu $\mathrm{C}$ was identified as to primarily consist of $\gamma$-alumina, along with a small fraction of amorphous aluminium oxide. The specific surface area could be determined using nitrogen sorption analysis $(77 \mathrm{~K})$, to be $102.1 \mathrm{~m}^{2} / \mathrm{g}$ (after BET-method [40]). The adsorption isotherms show no evidences of pores, and therefore, the average primary particle radius can be calculated as $10.1 \mathrm{~nm}$ from the BET surface area. These small particles are not present in solution, due to the formation of larger aggregates. Nevertheless, the thermodynamic properties of such a nanodispersed powder, fundamentally depend on the primary particle radius.

\subsection{Dissolution experiments}

The dissolution of Aluminiumoxid $\mathrm{C}$ was carried out in deionised water, in the $\mathrm{pH}$ range of 3.0 to 11.5 . The use of appropriate buffer solutions had to be avoided because of the large tendency of the $\mathrm{Al}^{3+}$-ion to form stable complexes with the larger part of the buffer components. On this account the $\mathrm{pH}$ was kept constant by adding small amounts of $\mathrm{HCl}$ or $\mathrm{KOH}$ standard solutions (Aldrich), during the entire dissolution period. The influence of the supersaturation/available surface area, was investigated by suspending the corresponding mass of the metal oxide in deionised water, yielding surface to volume (solvent) ratios of 6, 60 and $600 \mathrm{~m}^{2}$ per $100 \mathrm{~mL}$, respectively. In these special circumstances of dissolution experiments we comprehend the phrase supersaturation as the quotient of maximal achievable aluminum concentration (defined by the weighted in mass of metal oxide) and aluminum concentration under saturation conditions (depending on $\mathrm{pH}$, temperature, aluminum phase etc.), which can be derived by equation 5 . The solvent was thermostated at $25{ }^{\circ} \mathrm{C}$, mixed for at least 5 min after addition of the solid material, adjusted to the desired $\mathrm{pH}$ by adding the adequate volume of $\mathrm{HCl}$ or $\mathrm{KOH}$ standard solution and stored on a shaker at a constant temperature of $25{ }^{\circ} \mathrm{C}$. It was necessary to determine the $\mathrm{pH}$ of the suspension through time at appropriate intervals, throughout the entire dissolution experiment. Readjusting to the desired (initial) $\mathrm{pH}$ value had to be performed by adding small amounts of acid or base at times. Several dissolution experiments were carried out twice in order to test the reproducibility of results. The nomenclature of the experiments are given in a uniform mode (Axxxyyyz), containing the $\mathrm{pH}$ in the form xx.x, the surface to volume ratio $\mathbf{y y y}$ in $\mathrm{m}^{2}$ per $100 \mathrm{~mL}$, as well as a consecutive letter $(\mathbf{z})$ marking dissolution experiments under identical conditions. Table 1 gives a summary of the experimental parameters of the solubility experiments carried out in previous work [23], whereas Table 2 presents the corresponding parameters of the new experiments performed.

After selected dissolution times, a small volume of the suspension was separated by centrifugation (acceleration $\approx 6000 \mathrm{~g}$ ), filtered through a $200 \mathrm{~nm}$ and/ or a $25 \mathrm{~nm}$ syringe filter, respectively, diluted to a volume of $20 \mathrm{~mL}$ and acidified 
Table 1. Experimental parameters of the dissolution experiments using the synthetic $\gamma-\mathrm{Al}_{2} \mathrm{O}_{3}$ in deionised water at $25^{\circ} \mathrm{C}$ and $\mathrm{pH}$ values in the range 3.0 to 11.0 from previous work [23].

\begin{tabular}{|c|c|c|c|c|c|c|}
\hline \multirow[t]{2}{*}{ nomenclature } & \multicolumn{6}{|c|}{ experimental parameters } \\
\hline & $\begin{array}{l}m_{E}{ }^{a} \\
\text { in } \mathrm{g}\end{array}$ & $\begin{array}{l}S_{a}{ }^{b} \\
\text { in } \mathrm{m}^{2}\end{array}$ & $\begin{array}{c}V_{L}{ }^{c} \\
\text { in } \mathrm{mL}\end{array}$ & $\begin{array}{c}S_{a} / V_{L}{ }^{d} \\
\text { in } \mathrm{m}^{2} / 100 \mathrm{~mL}\end{array}$ & $\mathrm{pH}_{s}^{e}$ & $\mathrm{pH}_{L}^{f}$ \\
\hline A030060 & 3.0587 & 312.3 & 500 & 62.46 & 4.60 & 3.0 \\
\hline A035060a & 3.1110 & 317.6 & 500 & 63.53 & 4.57 & 3.5 \\
\hline A035060b & 3.0618 & 313.3 & 500 & 62.65 & 4.76 & 3.5 \\
\hline A040060a & 3.0535 & 311.8 & 500 & 62.35 & 4.65 & 4.0 \\
\hline A040060b & 3.0578 & 312.2 & 500 & 62.44 & 4.56 & 4.0 \\
\hline $\mathrm{A} 040060 \mathrm{c}^{\dagger}$ & 0.7485 & 71.18 & 100 & 56.95 & 4.03 & 4.0 \\
\hline A045060 & 3.1028 & 316.8 & 500 & 63.36 & 4.82 & 4.5 \\
\hline A050060 & 3.0552 & 311.9 & 500 & 62.39 & 4.73 & 5.0 \\
\hline A050060a & 3.0239 & 308.7 & 500 & 61.75 & 4.87 & 5.0 \\
\hline A050060b & 3.0668 & 313.1 & 500 & 62.62 & 4.52 & 5.0 \\
\hline A090060 & 3.0745 & 313.9 & 500 & 62.78 & 4.44 & 9.0 \\
\hline A100060 & 3.0578 & 312.2 & 500 & 62.44 & 4.70 & 10.0 \\
\hline A100060a & 3.0740 & 313.9 & 500 & 62.77 & 4.75 & 10.0 \\
\hline A105060a & 3.0661 & 313.0 & 500 & 62.61 & 4.52 & 10.5 \\
\hline A105060b & 3.0906 & 315.6 & 500 & 63.11 & 4.77 & 10.5 \\
\hline A110060a & 3.0776 & 314.2 & 500 & 62.84 & 4.62 & 11.0 \\
\hline A110060b & 3.0677 & 313.2 & 500 & 62.64 & 4.60 & 11.0 \\
\hline $\mathrm{A} 110060 \mathrm{c}^{\mathrm{g}}$ & 0.7481 & 57.90 & 100 & 46.32 & 7.70 & 11.0 \\
\hline \multicolumn{7}{|c|}{${ }^{a}$ mass of $\gamma-\mathrm{Al}_{2} \mathrm{O}_{3}$} \\
\hline \multicolumn{7}{|c|}{${ }^{b}$ surface area, available for dissolution process } \\
\hline \multicolumn{7}{|c|}{${ }^{c}$ volume of solution } \\
\hline \multicolumn{7}{|c|}{${ }^{d}$ surface/volume ratio } \\
\hline \multicolumn{7}{|c|}{${ }^{e} \mathrm{pH}$-value after addition of solid material } \\
\hline \multicolumn{7}{|c|}{${ }^{f}$ adjusted $\mathrm{pH}$ of dissolution experiment } \\
\hline \multicolumn{7}{|c|}{${ }^{\mathrm{g}}$ solid material from the previous dissolution experiment $\left(\mathrm{S}_{\mathrm{BET}}=95.1 \mathrm{~m}^{2} / \mathrm{g}\right.$ and $\left.77.4 \mathrm{~m}^{2} / \mathrm{g}\right)$} \\
\hline
\end{tabular}

with $\mathrm{HCl}$ to a $\mathrm{pH}$ of approximately 2.5 . Using dynamic light scattering, we were unable to detect primary particles as well as agglomerates of $\gamma$-alumina in all these solutions. The aluminium content dissolved was analytically determined by measuring the absorbance of the aluminium-eriochromcyanine complex in water. The absorbance of the solution is measured against a reagent blank, at a wavelength of $535 \mathrm{~nm}$. Each sample was determined fourfold and the concentration calculated via a calibration graph using eight $\mathrm{Al}^{3+}$-concentrations in the range 3.0 to $7.2 \mu \mathrm{g} \mathrm{Al}^{3+}$ per $25 \mathrm{~mL}$. To avoid a high blank absorbance, the use of polymethyl pentene flasks, double distilled water $(0.055 \mu \mathrm{S} / \mathrm{cm})$, and a $\mathrm{pH}$ of approximately 5.5 in the final solution are recommended. For a detailed description of the analytical method determining the aqueous aluminium content, see ref. [23]. Besides this spectrophotometric method, we used the ICP-OES 
Table 2. Experimental parameters of the new dissolution experiments using the synthetic $\gamma-\mathrm{Al}_{2} \mathrm{O}_{3}$ in deionised water at $25{ }^{\circ} \mathrm{C}$ and $\mathrm{pH}$ values in the range 3.0 to 11.5.

\begin{tabular}{|c|c|c|c|c|c|c|}
\hline \multirow[t]{2}{*}{ nomenclature } & \multicolumn{6}{|c|}{ experimental parameters } \\
\hline & $\begin{array}{l}m_{E}^{a} \\
\text { in } \mathrm{g}\end{array}$ & $\begin{array}{c}S_{a}^{b} \\
\text { in } \mathrm{m}^{2}\end{array}$ & $\begin{array}{c}V_{L}^{c} \\
\text { in } \mathrm{mL}\end{array}$ & $\begin{array}{c}S_{a} / V_{L}{ }^{d} \\
\text { in } \mathrm{m}^{2} / 100 \mathrm{~mL}\end{array}$ & $\mathrm{pH}_{s}^{e}$ & $\mathrm{pH}_{L}^{f}$ \\
\hline A030006 & 0.2930 & 29.92 & 500 & 5.984 & 4.77 & 3.0 \\
\hline A035006 & 0.2939 & 30.01 & 500 & 6.002 & 4.80 & 3.5 \\
\hline A040006 & 0.2940 & 30.02 & 500 & 6.004 & 4.67 & 4.0 \\
\hline A045006 & 0.2933 & 29.94 & 500 & 5.988 & 4.92 & 4.5 \\
\hline A090006 & 0.2933 & 29.94 & 500 & 5.988 & 4.76 & 9.0 \\
\hline A095006 & 0.2937 & 29.99 & 500 & 5.998 & 4.83 & 9.5 \\
\hline A100006 & 0.2935 & 29.97 & 500 & 5.994 & 4.81 & 10.0 \\
\hline A105006 & 0.2933 & 29.94 & 500 & 5.988 & 4.85 & 10.5 \\
\hline A110006 & 0.2931 & 29.93 & 500 & 5.986 & 4.76 & 11.0 \\
\hline A115006 & 0.2937 & 29.99 & 500 & 5.998 & 4.99 & 11.5 \\
\hline A095060 & 2.938 & 300.0 & 500 & 59.99 & 4.74 & 9.5 \\
\hline A030600 & 5.866 & 598.9 & 100 & 598.9 & 4.84 & 3.0 \\
\hline A035600 & 5.865 & 598.8 & 100 & 598.8 & 4.91 & 3.5 \\
\hline A040600 & 5.865 & 598.8 & 100 & 598.8 & 4.75 & 4.0 \\
\hline A045600 & 14.66 & 1497 & 250 & 598.7 & 4.89 & 4.5 \\
\hline A095600 & 14.67 & 1498 & 250 & 599.1 & 4.92 & 9.5 \\
\hline A100600 & 5.865 & 598.8 & 100 & 598.8 & 4.79 & 10.0 \\
\hline A 105600 & 5.866 & 598.9 & 100 & 598.9 & 4.92 & 10.5 \\
\hline A110600 & 5.865 & 598.8 & 100 & 598.8 & 4.92 & 11.0 \\
\hline $\mathrm{A} 0406000^{g}$ & 16.01 & 1635 & 100 & 1635 & 5.34 & 4.0 \\
\hline \multicolumn{7}{|c|}{${ }^{a}$ mass of $\gamma-\mathrm{Al}_{2} \mathrm{O}_{3}$} \\
\hline \multicolumn{7}{|c|}{${ }^{b}$ surface area, available for dissolution process } \\
\hline \multicolumn{7}{|c|}{${ }^{c}$ volume of solution } \\
\hline \multicolumn{7}{|c|}{${ }^{d}$ surface/volume ratio } \\
\hline \multicolumn{7}{|c|}{${ }^{e} \mathrm{pH}$-value after addition of solid material } \\
\hline \multicolumn{7}{|c|}{${ }^{f}$ adjusted $\mathrm{pH}$ of dissolution experiment } \\
\hline \multicolumn{7}{|c|}{$g$ suspension with $6000 \mathrm{~m}^{2} / 100 \mathrm{~mL}$ not possible due to inhomogeneities } \\
\hline
\end{tabular}

device SpectroFlame (by SPECTRO, Germany), to determine the aluminium content in solution as having a concentration smaller than $10^{-5} \mathrm{~mol} / \mathrm{L}$, as well as to verify the reproducibility of our data.

\subsection{Characterisation of the solid material}

The powder samples from the dissolution experiments were characterised by employing different methods. Therefore, a small volume of the suspension was removed from the running experiment and centrifuged at 2940/6050 $\mathrm{g}$ for at least 10 minutes. The samples were dried at $110{ }^{\circ} \mathrm{C}$ after a washing procedure 
with water (once), in order to remove adsorbed molecules and ions. The specific surface area after the BET method [40] was determined by multipoint nitrogen adsorption measurements at $77 \mathrm{~K}$, using the automatic volumetric sorption analyzer Autosorb-1, of Quantachrome Corporation. The adsorption isotherm of each sample was recorded twice, after evacuating at 100 and $350{ }^{\circ} \mathrm{C}$, respectively. The structural properties of these samples were investigated by X-ray (powder) diffraction measurements (XRD), using both the URD 6 (Freiberger Präzisionsmechanik, Mo-K ${ }_{\alpha}$ ) and D5000 (Siemens-Bruker, Cu-K ${ }_{\alpha}$ ) devices.

\section{Model considerations}

Dealing with the dissolution of nanodispersed $\gamma$-alumina, we are able to demonstrate the recent, successful application of a general theory. This approach is based on a proposal to model colloidal dispersions thermodynamically. Here, we were able to describe selected concentration profiles as having distinct and variable maxima. An explanation for the different dissolution behaviour as a function of $\mathrm{pH}$ and the influence of the bayerite formation however, is yet to be proposed.

In recent papers, a phenomenological thermodynamic and kinetic model has been suggested, which is able to discern every possible change occurring in a system of colloidal particles [23, 24, 38, 39]; nucleation, particle growth, Ostwald ripening, and dissolution of particles are thereby included. The Gibbs free energy, $g(r, z)$, can be calculated from an uniform point of view, as shown below.

$$
\begin{aligned}
g(r, z)= & \left(1-z r^{3}\right) \ln \left(y\left(1-z r^{3}\right)\right)-\frac{1}{a}\left(1-a z r^{3}\right) . \\
& \ln \left(1-a z r^{3}\right)+h z r^{2}-z r^{3} \ln b-\ln y
\end{aligned}
$$

All relations are derived for isothermal and isobaric conditions, whereas the system consists of a fixed number of monomer molecules, $N^{0}$, of the radius $r_{0}$, which are able to form particles, and a fixed number of solvent molecules. $a$, and $b$ are further constants which depend on the amounts of substances in the system, and $h$ is given below (Eq. 2). Equation 1, calculates the difference in Gibbs free energy, $\triangle_{c} g$, between an actual state of the system where both monomer molecules and particles are present, and the well-defined reference state. This state is characterised by the fact that only monomer molecules and molecules of the solvent are present in solution. All quantities in Eq. 1 are defined as dimensionless, by the relations shown in Eq. 2.

$$
\begin{aligned}
z=\frac{Z}{N^{0} k_{B} T} & =g(r, z) \\
h=\frac{\Delta_{p}}{r_{0}} & =\frac{4 \pi \sigma}{k_{B} T} r_{0}^{2}
\end{aligned}
$$


In reference to the above equation, while $r$ and $z$ represent the particle radius and number of particles, respectively, $\sigma$ represents the solid/liquid interfacial tension of the $\gamma$-alumina. $y$ stands for the initial supersaturation in the system, whereas $k_{\mathrm{B}}$ and $T$ signify the Boltzmann constant and temperature, accordingly. For a detailed description of the model and a discussion of the potential surface properties, see refs. [24, 38, 39].

Changes to the actual system should occur along the direction of the negative gradient of the free energy, which describes the largest difference in Gibbs free energy from an arbitrary state to a neighbouring one. The so-called gradient curves can be calculated, so as to solve the differential Eq. 3 by numerical methods.

$$
\frac{\mathrm{d} z}{\mathrm{~d} r}=\frac{\left(\frac{\partial g(r, z)}{\partial z}\right)_{r}}{\left(\frac{\partial g(r, z)}{\partial r}\right)_{z}}=\frac{r \cdot\left[-\ln \left(\frac{y b\left(1-z r^{3}\right)}{1-a z r^{3}}\right)+\frac{h}{r}\right]}{3 z \cdot\left[-\ln \left(\frac{y b\left(1-z r^{3}\right)}{1-a z r^{3}}\right)+\frac{2 h}{3 r}\right]}
$$

The calculations were performed using Mathematica software [41], and in accordance with the common irreversible thermodynamics, we used the following ansatz for the kinetics of our dissolution process.

$$
\frac{\mathrm{d} c_{\mathrm{L}}^{1}(1)}{\mathrm{d} t}=-k B\left(c_{\mathrm{L}}^{1}(1)\right) \cdot|\nabla g(r, z)|
$$

In Eq. 4, the actual concentration of the particle forming species, $c_{\mathrm{L}}^{1}(1)$, as a function of time, is assumed to depend on the magnitude of the gradient of Gibbs free energy. The factor $B\left(c_{\mathrm{L}}^{1}(1)\right)$, depends on the actual aluminium content in solution. The differential equation could also only be solved by numerical methods. Here, $k$ can be understood as representing the rate constant of the dissolution process.

The properties of the colloidal system regarding dissolution and particle formation, do not only depend on the chemistry of the nanodispersed material. A crucial influence results from the supersaturation, $y$, and the surface term, $h$, (containing $\sigma$ ) respectively. The distinctive interaction of these parameters leads to outstanding properties. In the case of titania [24] as well as $\gamma$-alumina nanoparticles [23], an unusual kinetic size-effect could be observed, leading to a distinct maximum in the concentration-time-curve. The application of the model considerations to the newer experimental data, could improve our understanding of the running processes.

\section{Results and discussion}

\subsection{Dissolution profiles}

By measuring the actual aluminium content in solution, we obtained the concentration profiles shown in Fig. 1, for experiments carried out at a surface to volume ratio of $60 \mathrm{~m}^{2} / 100 \mathrm{~mL}$ [23]. Here, and in further presentations, $c\left(\mathrm{Al}^{3+}\right)$ 

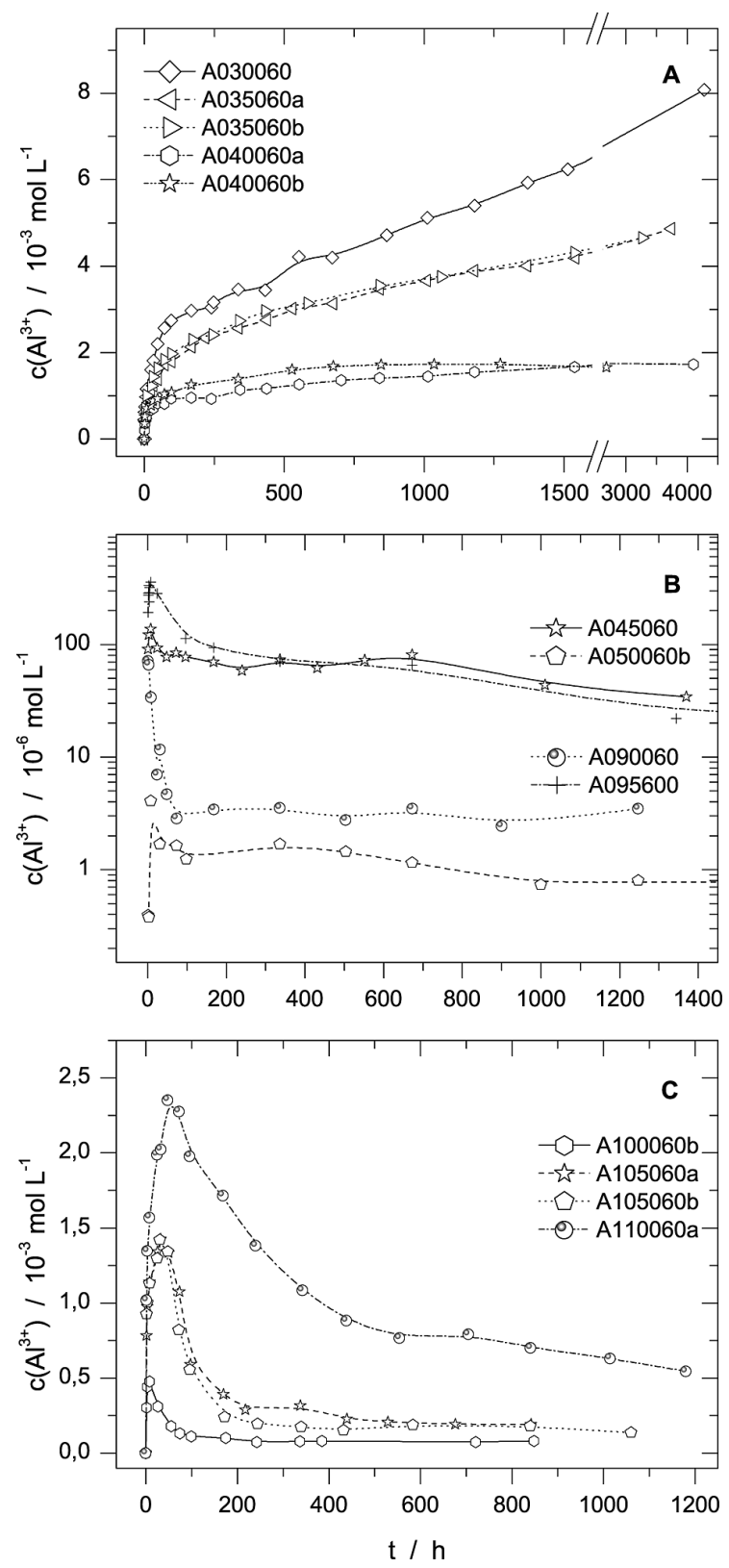

Fig. 1. Actual aluminium concentration as a function of time in the dissolution experiments carried out with $\gamma$-alumina at a surface to volume ratio of $60 \mathrm{~m}^{2} / 100 \mathrm{~mL}$. The $\mathrm{pH}$ was varied as followed: A 3.0-4.0, B 4.5-9.5, C 10.0-11.0. Results of previous experimental work [23] (consecutive lines for guiding the eyes). 
means the sum of the concentrations of all aluminium species present in solution. In diagram A of Fig. 1, the corresponding dissolution curves, within the $\mathrm{pH}$ range from 3.0 to 4.0, are illustrated. Here, dissolution behavior could be observed without any indication of a size effect taking place.

In contrast, the diagrams $\mathrm{B}$ and $\mathrm{C}$ in Fig. 1, represent concentration profiles where significant changes can be observed. Obviously, at higher $\mathrm{pH}$ values, we determined the expected dissolution curves showing distinct concentration maxima, due to a size effect of the metal oxide particles used. A closer inspection reveals differences in both the concentration value of the maximum, and the time when this maximal concentration is observed. The dissolution kinetics are, naturally, dependent on the experimental parameters.

In the case of dissolving titania nanoparticles in water, similar observations could be made [24], although the influence of several parameters had been investigated. As a result, the mass concentration exposed to the liquid phase, and the equivalent of surface to volume ratio or supersaturation, sequentially, was proposed to be responsible for the kinetic size effect observed Keeping all other experimental parameters constant, we determined the influence of the surface to volume ratio (supersaturation), on the dissolution kinetics of the synthetic $\gamma$-alumina. Figure 2, displays the corresponding concentration profiles obtained, when a smaller mass of the oxide $\left(6 \mathrm{~m}^{2} / 100 \mathrm{~mL}\right)$ is exposed to the liquid phase.

Significant differences can be discerned in the dissolution behaviour of $\gamma$-alumina, when altering the levels of supersaturation and hence surface to volume ratio. Consequently, the $\mathrm{pH}$ values in each of the three diagrams in Fig. 2, are the same as in Fig. 1, thus enabling a direct comparison to be drawn. It is incredible that the surface to volume ratio could have such a large influence on the concentration profiles determined. The maximal concentration, as well as the point in time when this value is observed, are a function of the mass concentration of the oxide exposed to the liquid phase. In the solubility experiment at $\mathrm{pH}=10.5$ (A105xxx, diagram $\mathrm{C}$ in Figs. 1 and 2), for example, the maximal aluminium concentration is determined to be $1.4 \cdot 10^{-3} \mathrm{~mol} / \mathrm{L}$ (A105060) and $4.5 \cdot 10^{-4} \mathrm{~mol} / \mathrm{L}$ (A105006), respectively. Additionally, the first values were observed after 30 to $48 \mathrm{~h}$, whereas the second value was only discovered after approximately 336 hours. The primary particle radius, which is commonly expected to be responsible for the size effect alone, was not subject to change. This evidence is affirmed by the experimental results obtained at a surface to volume ratio of $600 \mathrm{~m}^{2} / 100 \mathrm{~mL}$. Figure 3 shows the dissolution behaviour determined, although, until now, few experiments could be accomplished.

Returning to our example, the dissolution at $\mathrm{pH}=10.5$, we are able to discern that the maximum (A105600) has shifted to approximately $2.7 \cdot 10^{-3} \mathrm{~mol} / \mathrm{L}$, after only a few hours $(\approx 4 \mathrm{~h}$ ) of dissolution. The effect of surface to volume ratio on the aluminium concentration in the maximum is clearly developed. Such statements are applicable to all dissolution experiments carried out until now. Figure 4 presents the experimental results at selected $\mathrm{pH}$ values, where the influence of supersaturation/surface to volume ratio, on the shape of the concentra- 

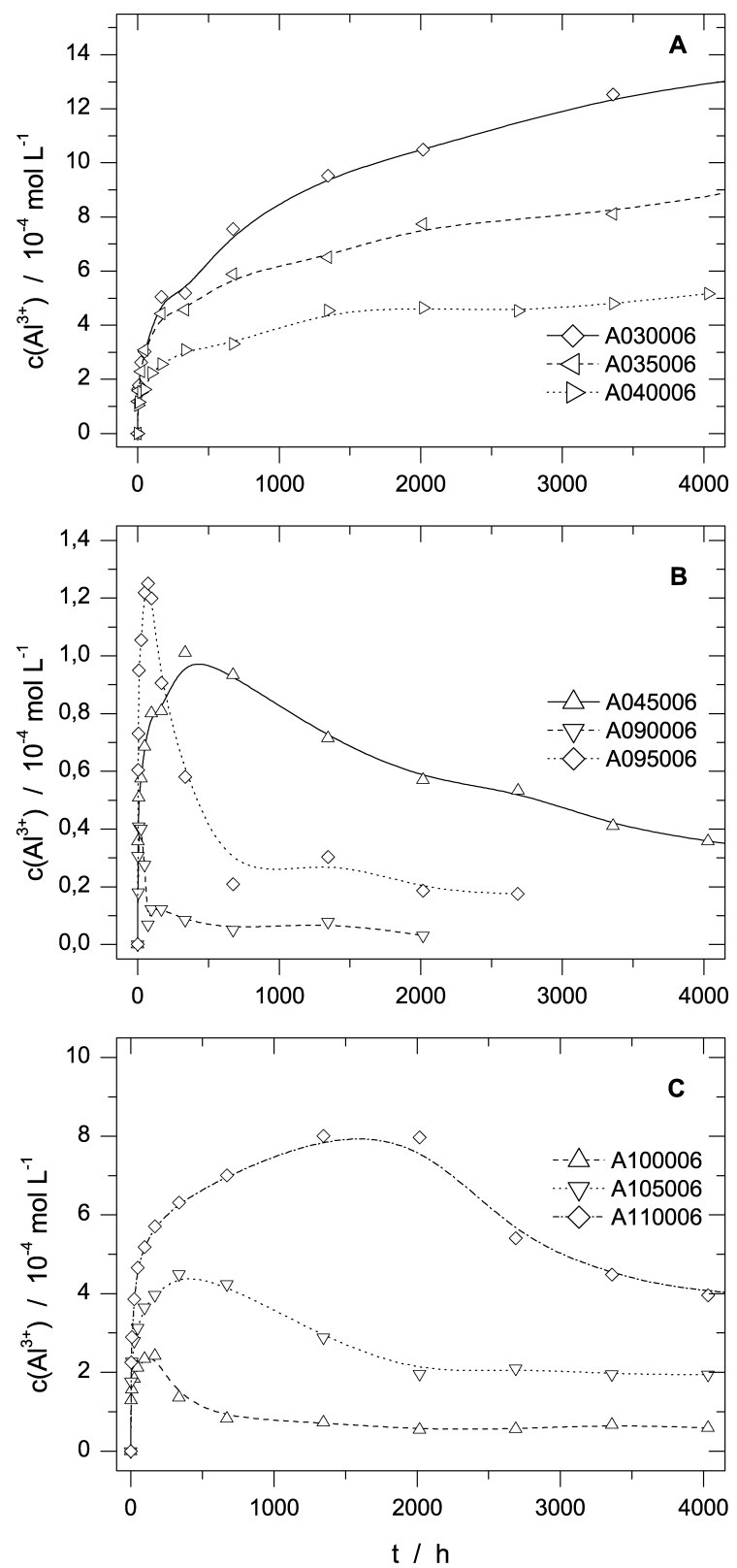

Fig. 2. Actual aluminium concentration as a function of time in the dissolution experiments carried out with $\gamma$-alumina at a surface to volume ratio of $6 \mathrm{~m}^{2} / 100 \mathrm{~mL}$ and different $\mathrm{pH}$ values (A 3.0/3.5/4.0, B 4.5/9.0/9.5, C 10.0/10.5/11.0) (consecutive lines for guiding the eyes). 


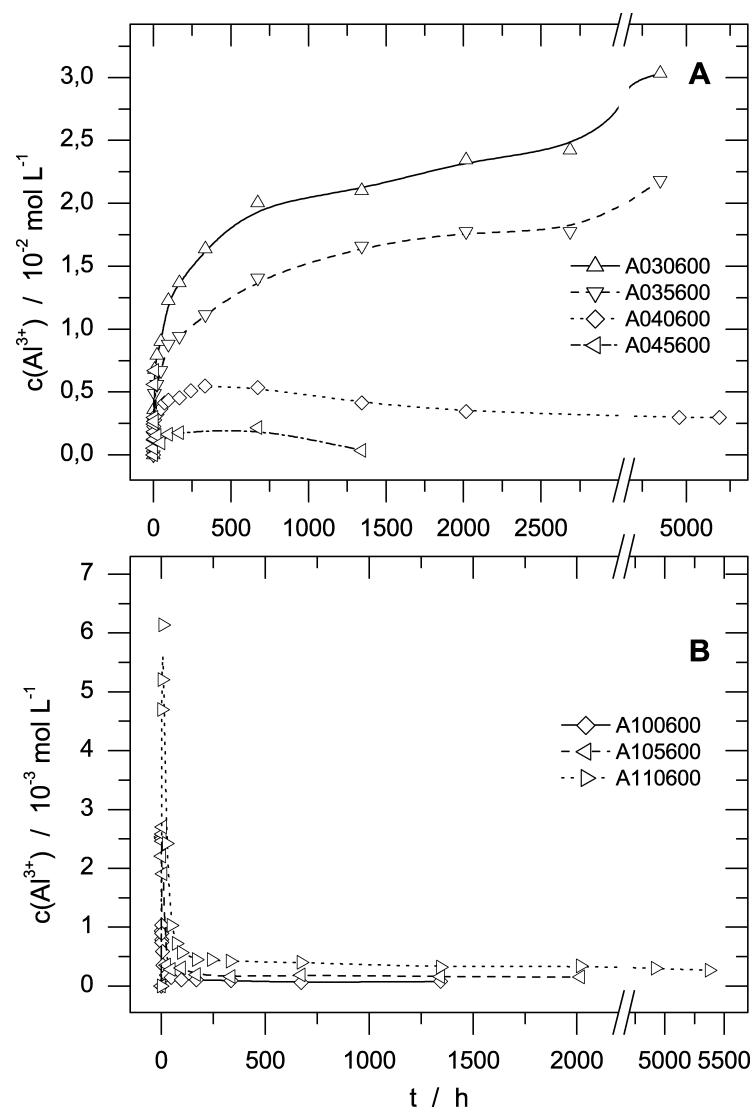

Fig. 3. Actual aluminium concentration as a function of time in the dissolution experiments carried out with $\gamma$-alumina at a surface to volume ratio of $600 \mathrm{~m}^{2} / 100 \mathrm{~mL}$ and different $\mathrm{pH}$ values (A 3.0/3.5/4.0/4.5, B 10.0/10.5/11.0) (consecutive lines for guiding the eyes).

tion profiles can clearly be recognised. Each diagram contains a magnified section, detailing the actual aluminium concentration at the beginning of the dissolution experiment. Looking in detail at Fig. 4, it can be noted, that we were unable to accurately determine the concentration maximum for high supersaturation, due to excessively fast dissolution kinetics, which resulted in gaps in the experimental data.

Increasing the mass of the oxide exposed to the same volume of the liquid phase by factor 100 , leads to concentration values in the maximum being, approximately, one order of magnitude higher, approximately. Additionally in this case, the point in time when maximal aluminium concentrations were determined, had shifted to shorter dissolution times, by roughly a factor of $1 / 100$.

In previous work [23] we were unable to observe a size effect at lower $\mathrm{pH}$ values. Diagram A of Fig. 3, shows the corresponding dissolution profiles at 

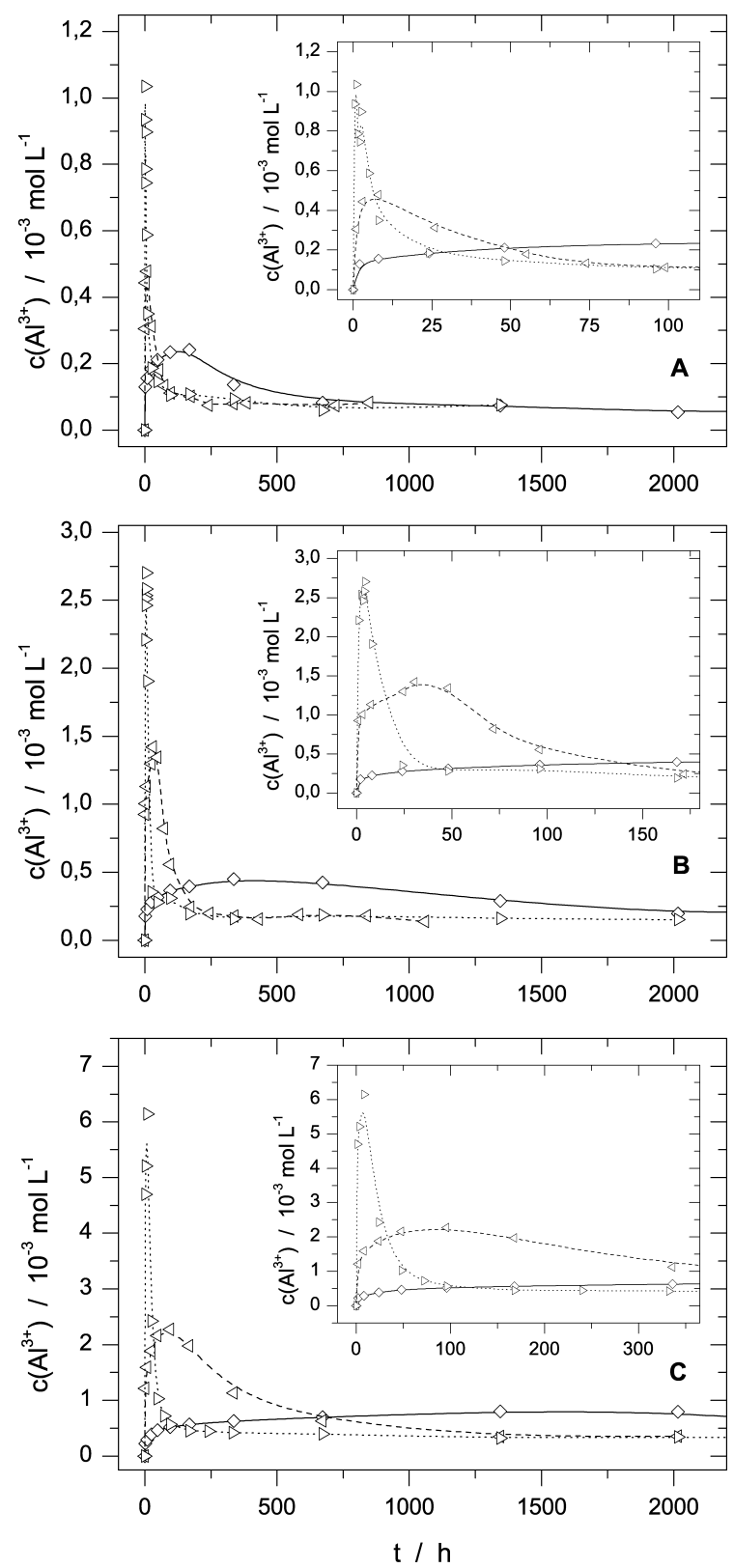

Fig. 4. Actual aluminium concentration as function of dissolution time and different surface to volume ratio of $6(\diamond), 60(\nabla)$, and $600 \mathrm{~m}^{2} / 100 \mathrm{~mL}(\triangleright)$. The solubility experiments in each of the diagrams were carried out at the same $\mathrm{pH}$ which are $10.0(\mathbf{A}-\mathrm{A} 100 \mathrm{xxx}), 10.5$ (B A105xxx), and 11.0 (C - A110xxx) (consecutive lines for guiding the eyes). 
$600 \mathrm{~m}^{2} / 100 \mathrm{~mL}$. One can clearly recognise that a maximum is present when dissolving $\gamma-\mathrm{Al}_{2} \mathrm{O}_{3}$ at $\mathrm{pH}=4.0$ (A040600), and by applying our theoretical model, we were able to predict this behaviour.

\subsection{Solid phase properties}

Another question arises from the formation of bayerite determined in the previous dissolution experiments [23]. The formation of a less soluble phase had to cause changes in the dissolution behaviour. If we analyze the constant concentrations at the end of each solubility experiment, and consider the actual species distribution of all possible aqueous $\mathrm{Al}^{3+}$-complexes, the solubility constant can be determined. The value obtained in previous work [23], coincide with the corresponding values for bayerite, as proposed in the following literature [27]. As commonly expected, we can see here that the less soluble, solid phase, defines the saturation concentration.

Despite an already evident size effect, the observed maximum could also be influenced by the phase formation of bayerite. We were unable to characterise the phase composition in the majority of experiments, due to a lack of sample material. Only in solubility tests with a high surface to volume ratio (Axxx600), there existed the possibility to separate a small volume of suspension, and therefore obtain an appropriate amount of solid material. In doing so, we obtained results of XRD measurements and nitrogen sorption analysis, as shown in Figs. 5 and 6, respectively. The diffraction pattern for two dissolution experiments are provided in Fig. 5.

The diffraction patterns for the dissolution experiment at $\mathrm{pH}=4.0$ (A040600, diagram A in Fig. 5), only show evidence of a new phase formed (\#) at $1344 \mathrm{~h}$ and beyond. These reflexes can be attributed to gibbsite or amorphous aluminium (oxo-)hydroxide. From these discrete measurements, we can only conclude that the phase formation has not initiated during the first 672 hours. The concentration profile maximum, could, however, be determined after approximately $400 \mathrm{~h}$ instead (see diagram A in Fig. 3), showing no significant correlation with the existence of the phase alteration. This behaviour corresponds with the results of previous work [23], where no maximum could be observed in the concentration profiles of the dissolution experiments at $\mathrm{pH} \leq 4.0$. Here, we were only able to obtain few (and discrete) data points, which prevent us from issuing a conclusive general statement. In the case of dissolution experiment A110600 $(\mathrm{pH}=$ 11.0), the formation of a new phase had already occurred, within the timeframe of the first recorded diffraction pattern to show distinct reflexes (*) at $2 \Theta$-values of $18.7^{\circ}, 20.3^{\circ}$ and $40.5^{\circ}$, sequentially. These reflexes can be attributed to bayerite, formed from the aqueous solution. The concentration profile maximum was then observed between 8 and 24 hours instead (see diagram B in Fig. 3), and therefore, there is no definitive correlation between the concentration maximum and the occurrence of the phase formation.

As a result, the formation of the new phase had already been in progress, as well as not yet begun, when the maximum in the concentration profile could be 


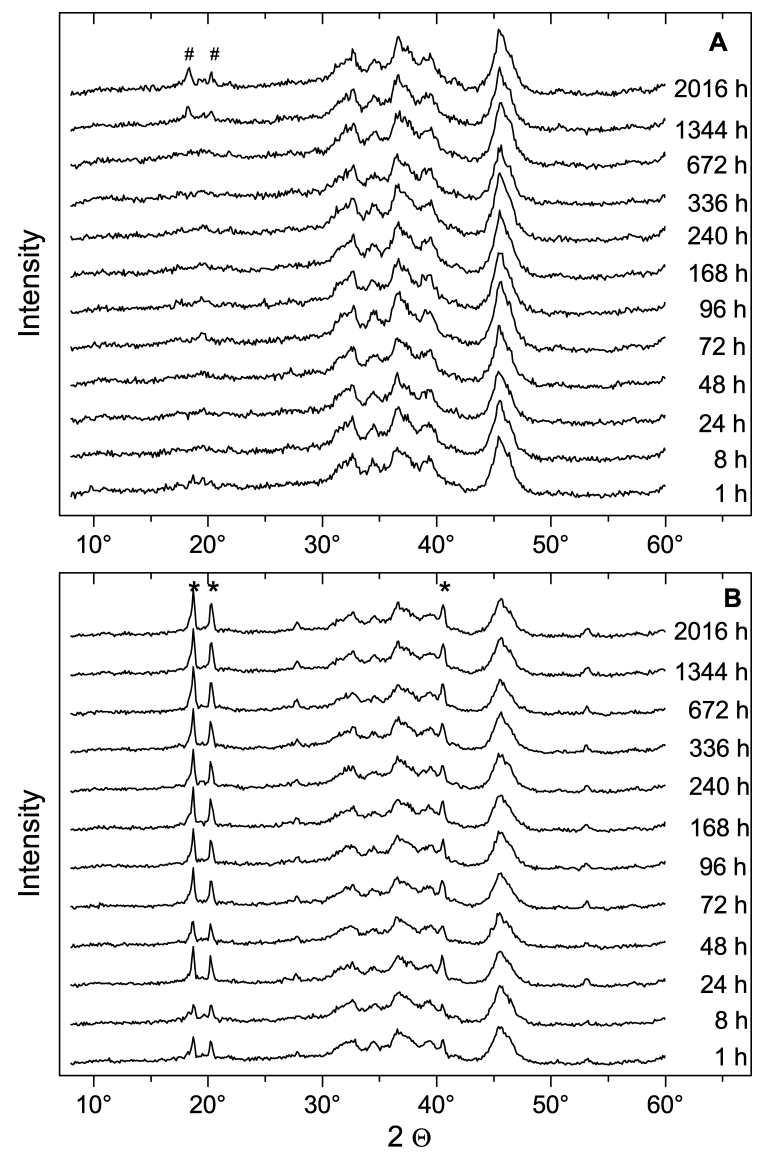

Fig. 5. X-ray powder diffraction pattern of solid samples collected during the running dissolution experiment at a surface to volume ratio of $600 \mathrm{~m}^{2} / 100 \mathrm{~mL}$. The times after start of the dissolution experiments (A - A040600; B - A110600) when the samples were collected are maintained. For further information see text.

determined. In reference to this, we can exclude from our assumptions, that the bayerite formation caused the maximum in aluminium concentration observed in these cases. It is highly presumable that this statement can be generally applied to all experiments, a fact which is strengthened by experimental results of dissolving titania nanoparticles [24], although experimental data only exists in relation to selected dissolution experiments. In the case of titania nanoparticles, similar observations could be made, even though the influence of a new phase formation is highly improbable. Naturally, the formation of a less soluble phase, has to have an influence on the actual $\mathrm{Al}^{3+}$-concentration. Evidently, this contribution is small compared to the size effect taking place, however, it nevertheless 

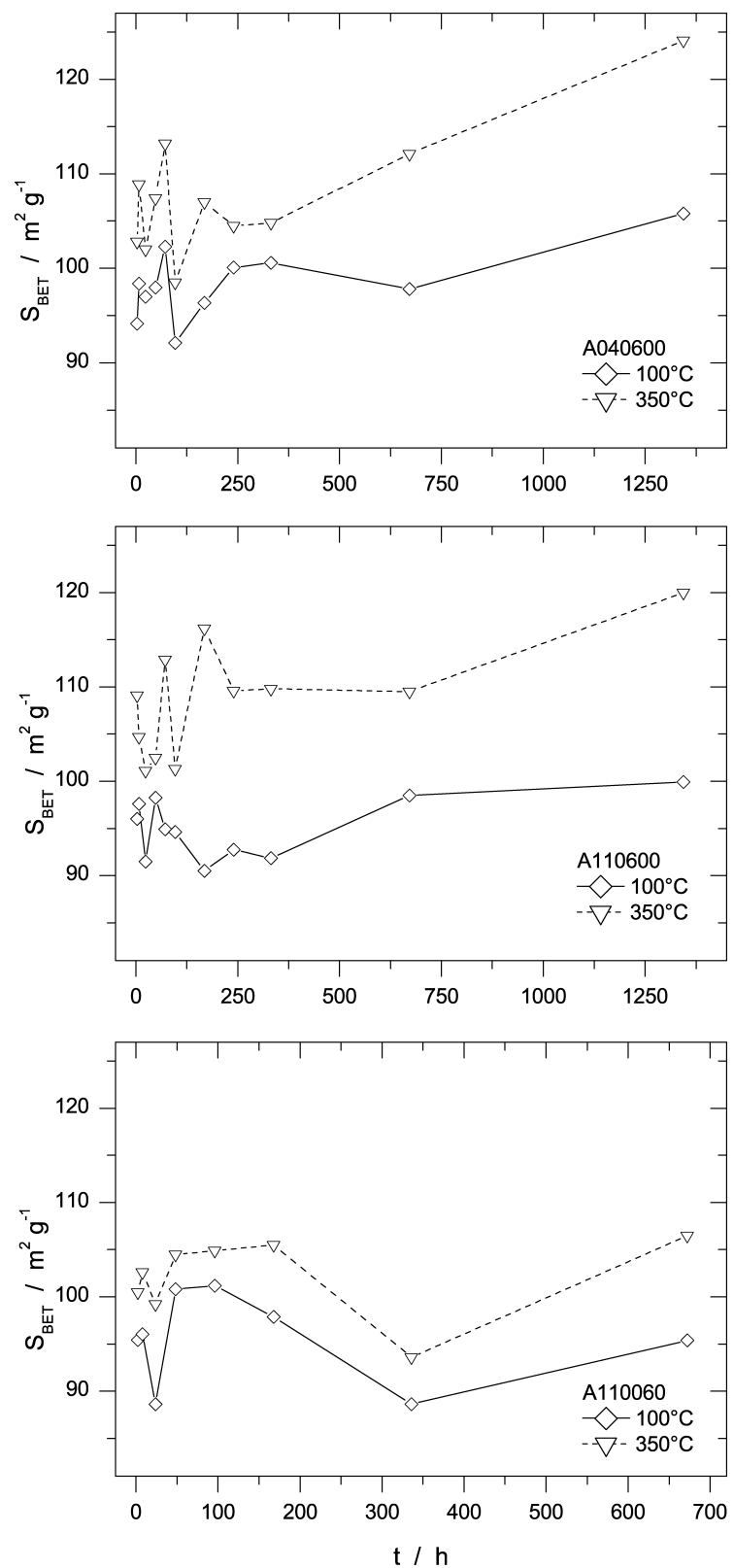

Fig. 6. Specific surface area (after BET method [40]) as function of dissolution time for selected experiments. The surface areas were determined after evacuating both at 100 and $350{ }^{\circ} \mathrm{C}$. 
acquires significance in relation to saturation conditions at the end of the dissolution process.

We noted that the surface area of the dispersed aluminium oxide altered during the dissolution process. Our considerations of the theoretical model [38, 39], enable us to predict fundamental alterations, which could be observed in the case where nanodispersed amorphous silica had been dissolved [39]. In principle, similar behaviour should be evident when using $\gamma$-aluminium oxide as solid material. Therefore, we performed nitrogen adsorption measurements in such cases where an appropriate (at least $100 \mathrm{mg}$ ) amount of substance was available, after the necessary pre-treatment of solid samples.

Firstly, the sample material had to be evacuated at elevated temperatures before recording the sorption isotherm. This procedure can causes profound problems, because the thermal phase conversion of aluminium oxide hydrates, already takes place in a temperature range of about 150 to $200{ }^{\circ} \mathrm{C}$ (especially bayerite) [42-48]. Therefore, we evacuated the solid samples first at $100{ }^{\circ} \mathrm{C}$, to determine the sorption isotherm, prior to repeating this treatment at $350{ }^{\circ} \mathrm{C}$ again, according to our previous investigations [23]. The results are presented in Fig. 6, displaying for three solubility experiments. The influence of temperature, on the surface area, during evacuation, is clearly pronounced in each diagram. Obviously, the pre-treatment (separation, wash procedure) of the sample material, influences the results of the nitrogen adsorption measurements, and as a result, only a general trend can be derived from the illustration. With increasing dissolution time, the specific surface area becomes greater at both temperatures. The differences between the two evacuation temperatures, arise from both the degree of water removal occupying a number of surface sites, but mainly from the phase conversion of the aluminium hydroxide into transition aluminas. This conversion results in a more fractal surface, due to a reduction in the volume of the solid phase. Interpreting the data is extremely difficult, because the surface morphology is simultaneously influenced by several experimental parameters. Considering the effects arising from the dissolution process, the use of the corresponding surface areas obtained after evacuation at $100{ }^{\circ} \mathrm{C}$, is recommended. According to our theoretical suppositions, an initial increase of the specific surface area should be determined experimentally. Nevertheless, problems arising from sample (pre-)treatment and experimental difficulties, added complications to the surface data interpretation, within respect to the predictions generated using our theoretical model. The kinetic size effect should be influenced by both, amount of specific surface area and chemical structure of the surface. It is also observed in the case of silica, if appropriate conditions are applied [49]. The properties of surface $\mathrm{OH}$-groups and adsorbed water are favourably characterized by NMRspectroscopy in case of silica samples [50, 51]. It is expected that changes of the properties of these surface species are also of evidence during the dissolution process of aluminium oxide. Therefore, NMR measurements could provide a further confirmation of the kinetic size effect. 


\subsection{Theoretical modelling}

The experimental dissolution curves, can be evaluated with the assistance of the thermodynamic and kinetic considerations already discussed. Figure 7 indicates the surface of the Gibbs free energy of cluster formation, $g(r, z)$, as function of cluster radius $r$ and cluster concentration $z$. This calculation was performed for the dissolution experiment $\mathrm{A} 110060\left(\mathrm{pH}=11.0,25^{\circ} \mathrm{C}\right)$. An important parameter to be considered when calculating the free energy surface of nucleation, $g(r, z)$, is the interfacial energy $\gamma$-alumina/water. Because of data absent from the literature, we estimated it to be $0.63 \mathrm{~N} / \mathrm{m}$.

For a detailed discussion of the special properties of the surface of $g(r, z)$, see refs. [38, 39]. The two blue lines labelled 6 and 7 in Fig.7, indicate possible developments of colloidal suspensions in a dissolution experiment. The entire quantity of colloid forming particles was placed into the pure solvent at the beginning of the experiment. Here, the starting point is located at the borderline of the domain of $g(r, z)$. The development of the colloidal system during the dissolution process, can be better described, by referring to Fig. 8. Here, three contour plots are presented, where, the fine black lines represent the isolines of $g\left(r, z_{\mathrm{s}}\right)$, the thick blue lines indicate the bottom of the valley, and the broken lines signify the calculated gradient curves after Eq. 3 . The starting point of the dissolution process is defined as the point indicated with an open circle. This point is located at the borderline $\mathrm{B}$, which describes all states where only particles and pure solvent molecules are present. The subscript $s$ at the particle concentration $z$, indicates that this quantity is scaled during the calculation, due to an improvement in the numerical approximation by a factor of $1.26 \cdot 10^{-7}$. In this case, the starting values of $r$ and $z$, have the same numerical value at the beginning of the dissolution process; the system develops along the broken curves during thedissolution process.

Therefore, the concentration maximum is a product of equilibrium concentration concerning the Kelvin equation $[52,53]$, of a resultant particle smaller than the initial particle. Afterwards, the cluster radius has again increased, whereas the cluster concentration remains reduced; simultaneously, the actual aluminium concentration must therefore be reduced. This process of growing particles is frequently observed, and is referred to as Ostwald ripening.

We can clearly note, that significant differences in the properties of $g\left(r, z_{\mathrm{s}}\right)$, and therefore in the gradient curves, exist when the surface to volume ratio has been changed under otherwise identical conditions. From the theoretical standpoint, a size effect is predicted in each experiment, but qualitative differences are expected, however. Applying the rate law in Eq. 4 to our experimental data, we should be able to describe the dissolution curves both qualitatively and quantitatively. As a result, we could determined the rate constant of the dissolution process. In this context, we were able to achieve the fitted model curves presented in Fig. 9, for the dissolution experiments at a $\mathrm{pH}$ value of 10.5 and 11.0, respectively. 


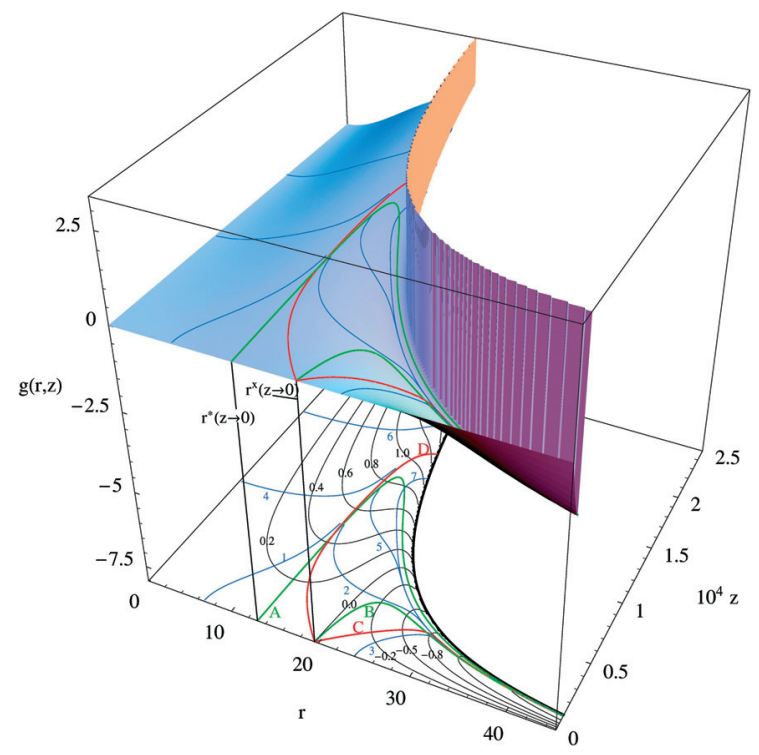

Fig. 7. Surface of the Gibbs free energy of cluster formation, $g(r, z)$, calculated for the parameters of the dissolution experiment $\mathrm{A} 110060\left(\mathrm{pH}=11.0,25{ }^{\circ} \mathrm{C}, 60 \mathrm{~m}^{2} / 100 \mathrm{~mL}\right)$. A detailed description of the properties is given in the text.

It can be discerned from Fig. 9, that our theoretical model has the potential to describe the experimentally obtained $\mathrm{Al}^{3+}$-concentration, as a quantitative and qualitative function of dissolution time, even though not all fits could be performed with success. The reasons for this behaviour are difficulties arising from the numerical calculations, if the $g(r, z)$-surface is very steep on one side and very flat on the other. When considering the experimental data points and the theoretical graphs in each diagram, records show that only one parameter was changed during the fitting procedure. This is the supersaturation, $y$, which depends on the $\mathrm{pH}$ of the dissolution system, molar mass of the metal oxide, $M$, the specific surface area, $S_{B E T}$, and the surface/volume ratio, $S_{a} / V_{L}$, as demonstrated by the following equation:

$$
y(p H)=\frac{c_{\max }}{c_{\text {sat }}(p H)}=\frac{2 S_{a} / V_{L}}{M S_{B E T} c_{s a t}(p H)} .
$$

The factor "2" in Eq. 5 considers that two aluminium atoms are present in the molecular formula of $\gamma$-alumina. This $\mathrm{pH}$ dependency, is a result of the fact that the saturation concentration and solubility of the metal oxide, is a function of proton/hydroxide concentration in solution. Therefore, when investigating the dissolution processes at different $\mathrm{pH}$ levels, but under the same surface-to-volume ratio, the supersaturations differ and the extent of the size effect may be subject to changes. 

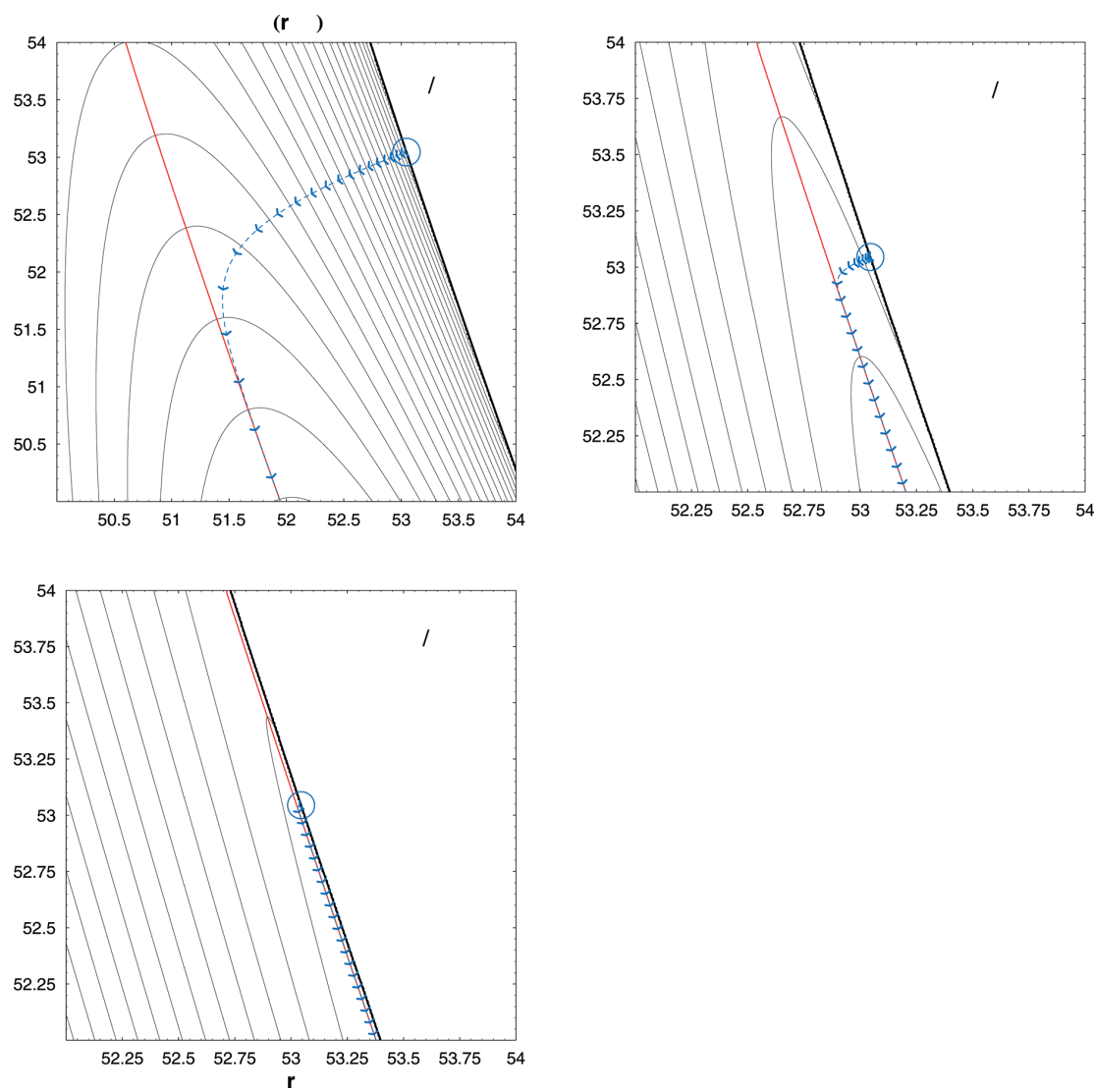

Fig. 8. Corresponding section (contour plot) of the Gibbs free energy surface belonging to the dissolution experiment at $\mathrm{pH}$ of 11 for different surface to volume ratios (supersaturations). The broken blue line in each diagram indicates the so-called gradient curve (Eq. 3) which describes the development of the dissolution system. These graphs quickly approach the bottom of the valley of $g\left(r, z_{\mathrm{s}}\right)$ (red graph).

The calculation of the rate constant, $k$, of the dissolution process, simply follows from Eq. 4. However, the particle concentration, $z$, is scaled during this process, due to a better numerical approximation. Therefore, the obtained values for $k$, have to be considered in relation to the scaling procedure $\left(k_{s}\right)$. Table 3 , summarises the rate constants obtained for selected experimental dissolution profiles. The numerical constant, $k$, as well as the appropriate rate constants, $k_{s}$, are provided, whereas $k_{s}$ considers both the scaling factor from the numerical calculation, and the amount of the surface available for the dissolution process. In the case of experiment A105600, no appropriate fit could be achieved. 


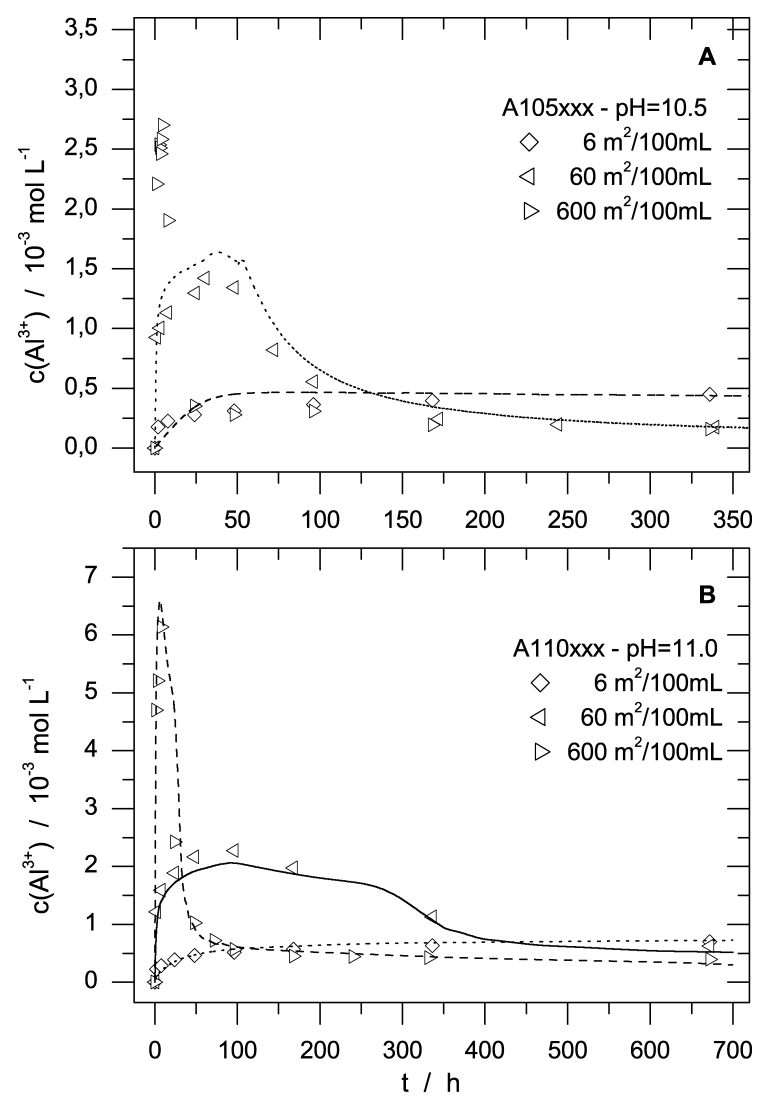

Fig. 9. Results of the non-linear regression of our thermodynamic and kinetic model function to selected dissolution experiments with $\gamma-\mathrm{Al}_{2} \mathrm{O}_{3}$ at two $\mathrm{pH}$ values. Each diagram contains the experimental dissolution profiles obtained by changing the surface/volume ratio (supersaturation) at otherwise identical conditions. (Missing consecutive line - no fit achievable.)

\section{Conclusions}

The process of dissolving nanodispersed $\gamma$-alumina, resulted in an observable, special solubility behaviour. In this current work, we have investigated the dissolution of aluminium oxide as a function of $\mathrm{pH}$ and of the mass of solid exposed to the solvent. Varying the mass of the $\gamma$-alumina, has enabled us to produce decisive differences in the solubility conditions, because the available surface area, as well as the supersaturation in the system, are altered as a result. Our experimental data confirmed the predicted influence on the dissolution process; by altering the surface to volume ratio, significantly modified concentration profiles were observed. Consequently, the extent of the size effect became evident in two ways. First, the maximal aluminium concentration observed, raises with 
Table 3. Rate constants for the dissolution process of $\gamma-\mathrm{Al}_{2} \mathrm{O}_{3}$ in water at $25{ }^{\circ} \mathrm{C}$ (selected experiments only) as the result of the numerical regression of the model function and the rate law (Eq. 4) to the experimental measurements.

\begin{tabular}{cccccc}
\hline experiment & $\begin{array}{c}S_{a} / V_{L} \\
\left(\mathrm{~m}^{2} / 100 \mathrm{~mL}\right)\end{array}$ & \multicolumn{2}{c}{ rate constant } & $\begin{array}{c}\text { super- } \\
\text { saturation }(y)\end{array}$ & $\begin{array}{c}\text { saturation conc. } \\
c_{\text {sat }}(\mathrm{mol} / \mathrm{L})\end{array}$ \\
\hline A105xxx & 006 & \multicolumn{5}{c}{$\left.0.104_{6} \mathrm{~h}^{-1}\right)$} & $\begin{array}{c}k_{s}\left(10^{-12} \mathrm{~mol}\right. \\
\left.\mathrm{m}^{-2} \mathrm{~s}^{-1}\right)\end{array}$ & $0.971_{6}$ & 127.8 & \\
& 060 & $5.59_{1}$ & $5.02_{1}$ & 1321 & $0.90 \times 10^{-4}$ \\
& 600 & \multicolumn{2}{c}{ no fit achievable } & & \\
A110xxx & 006 & $0.193_{9}$ & $1.80_{0}$ & 22.54 & \\
& 060 & $2.67_{1}$ & $2.36_{7}$ & 231.6 & $5.10 \times 10^{-4}$ \\
& 600 & $16.0_{1}$ & $7.42_{1}$ & 2258 & \\
\hline
\end{tabular}

increasing mass of the solid phase exposed to the same volume of the solvent. Concurrently, the point in time when this maximum is determined, had shifted to lower dissolution times in all cases. In a previous work [23], we reported that at $\mathrm{pH} \leq 4.0$ no size effect could be observed. By repeating these experiments with a higher surface to volume ratio $\left(600 \mathrm{~m}^{2} / 100 \mathrm{~mL}\right)$, the predicted size effects during the dissolution of $\gamma$-alumina, could be determined. When dissolving the oxide at a pH of 4.0 (A040600), a maximum appeared after approximately 400 hours, with an increased concentration value in comparison to the original experiment. In the experiments using still lower $\mathrm{pH}$ values, we could not observe a maximum in the concentration profiles until now. Obviously, the dissolution time needed to reach the expected maximum is too large, due to the fact that the size effect could not temporally be acquired. Consequently, our solubility experiments have to be continued, possibly up to a duration of one year, in order to solidify the results. When comparing the results of solubility experiments performed at the same level of $\mathrm{pH}$, but different (three) surface to volume ratio one can observe the distinct influence of both (primary) particle radius and supersaturation on the dissolution behavior. The available surface area of the oxide or supersaturation, respectively, exert influence on the kinetics of the dissolution process. Increasing the surface to volume ratio, leads to a shortening of time which is necessary to reach the concentration maximum; there exists an inversely proportional relationship between the two values. At the same time, when the rate constant is increased significantly, and the maximal aluminium concentration raises, without changing the primary particle radius. On this account, we had recently proposed $[23,24]$, that it is reasonable using the phrase "unusual kinetic size effect", to satisfy all factors which are responsible for the observed dissolution behaviour. We can conclude, that the extent of the size effect during the dissolution of nanodispersed substances, not only depends on the primary particle radius and the interfacial energy, which is provided by the famous Kelvin equation [52, 53], but also on the interaction of these parameters with the initial supersaturation in the system, additionally. This is not only a feature of this particular experiment, but a universal property of colloidal systems. 
The application of XRD measurements, resulted in evidence that the formation of the new phase (bayerite), occurred within few hours, and without any correlation to the observed concentration maximum. Therefore, an influence or reason for this phenomenon in relation to the special dissolution behaviour, can be excluded. Nevertheless, the equilibrium concentrations determined at the end of each dissolution experiment, are due to new phases formed. In addition, we can assert that the formation of bayerite has an influence on the surface morphology. So, the specific surface area is found to increase, despite the expected decrease, which is caused by the initial Ostwald-ripening of the particles at longer dissolution times. The hydrothermal changes of the solid material from the dissolution experiments, are easily identifiable and result in significant differences in the surface morphology. In conclusion this behaviour can be attributed to the bayerite phase, which undergoes a phase transition to transition aluminas, during this treatment.

\section{Acknowledgement}

The authors would like to thank Dr. Dirk Merten, who carried out the ICP-OES measurements, and acknowledge both Dr. Bernd Müller and Dr. Matthias Müller for their contribution of the X-raydiffraction measurements. All person mentioned are employees at the Friedrich-Schiller-University Jena.

\section{References}

1. H. H. Pohland, Aluminiumoxid: Herstellung, Eigenschaften, Einsatzgebiete. Verl. Moderne Industrie, Landsberg/Lech (1998) vol. 176 of Die Bibliothek der Technik.

2. E. Müller and C. Oestrich (Eds.), Handling of highly dispersed powders: Priority research program (German Research Foundation). Shaker Verlag, Aachen (2004).

3. V. A. Pokrovskii and H. C. Helgeson, Can. Mineral. 29(4) (1991) 909.

4. M. Schacht, N. Boukis, and E. Dinjus, J. Mater. Sci. 35(24) (2000) 6251.

5. I. Balint, A. Miyazaki, and K.-I. Aika, Chem. Mater. 13(3) (2001) 932.

6. M. Szekeres, E. Tombácz, K. Ferenczand, and I. Dékány, ACH-Models Chem. 134(6) (1997) 865.

7. Y. W. Kim and J. K. Baird, J. Phys. Chem. B 109(36) (2005) 17262.

8. K. H. Gayer, L. C. Thompson, and O. T. Zajicek, Can. J. Chem. 36 (1958) 1268.

9. N. M. Johnson, C. T. Driscoll, J. S. Eaton, G. E. Likens, and W. H. McDowell, Geochim. Cosmochim. Acta 45 (1981) 1421.

10. B. Sanjuan and G. Michard, Geochim. Cosmochim. Acta 51 (1987) 1823.

11. G. Verdes, R. Gout, and S. Castet, Eur. J. Mineral. 4 (1992) 767.

12. D. J. Wesolowski, Geochim. Cosmochim. Acta 56(3) (1992) 1065.

13. D. J. Wesolowski and D. A. Palmer, Geochim. Cosmochim. Acta 58(14) (1994) 2947.

14. H. Li, J. Addai-Mensah, J. C. Thomas, and A. R. Gerson, J. Colloid Interf. Sci. 286 (2005) 511.

15. M. Dietzel and G. Böhme, Geochim. Cosmochim. Acta 69(5) (2005) 1199.

16. M. Szekeres, E. Tombácz, K. Ferencz, and I. Dékány, Colloids Surf. A 141 (1998) 319.

17. E. Tombácz and M. Szekeres, Langmuir 17(5) (2001) 1411. 
18. E. Tombácz, M. Szekeres, and E. Klumpp, Langmuir 17(5) (2001) 1420.

19. M. Digne, P. Sautet, P. Raybaud, P. Euzen, and H. Toulhoat, J. Catal. 211 (2002) 1 .

20. H. A. Al-Abadleh and V. H. Grassian, Langmuir 19 (2003) 341.

21. B. Kasprzyk-Hordern, Adv. Colloid Interf. Sci. 110 (2004) 19.

22. T. H. Yoon, S. B. Johnson, C. B. Musgrave, and G. E. Brown Jr., Geochim. Cosmochim. Acta 68(22) (2004) 4505.

23. F. Roelofs and W. Vogelsberger, J. Colloid Interf. Sci. 303 (2006) 450.

24. J. Schmidt and W. Vogelsberger, J. Phys. Chem. B 110(9) (2006) 3955.

25. R. E. Mesmer and C. F. Baes Jr., Inorg. Chem. 10(10) (1971) 2290.

26. C. F. Baes and R. B. Mesmer, The hydrolysis of cations. Wiley, New York (1976).

27. W. L. Lindsay, Chemical Equilibria in Soils. Wiley, New York (1979) chapter 3.

28. J. W. Akitt and J. M. Elders, J. Chem. Soc. Dalton 5 (1988) 1347.

29. G. Furrer, C. Ludwig, and P. W. Schindler, J. Colloid Interf. Sci. 149(1) (1992) 56.

30. D. A. Palmer and D. J. Wesolowski, Geochim. Cosmochim. Acta 57 (1993) 2929.

31. B. C. Faust, W. B. Labiosa, K. H. Dai, J. S. MacFall, B. A. Browne, A. A. Ribeiro, and D. D. Richter, Geochim. Cosmochim. Acta 59(13) (1995) 2651.

32. G. Sposito, The environmental chemistry of aluminum. Lewis Publishers, Boca Raton (1996).

33. G. Furrer, M. Gfeller, and B. Wehrli, Geochim. Cosmochim. Acta 63(19/20) (1999) 3069.

34. B. L. Phillips, W. H. Casey, and M. Karlsson, Nature 404 (2000) 379.

35. A. P. Lee, G. Furrer, and W. H. Casey, J. Colloid Interf. Sci. 250 (2002) 269.

36. B. L. Phillips, A. P. Lee, and W. H. Casey, Geochim. Cosmochim. Acta 67(5) (2003) 2725 .

37. J. R. Rustad, J. S. Loring, and W. H. Casey, Geochim. Cosmochim. Acta 68(14) (2004) 3011.

38. W. Vogelsberger, J. Phys. Chem. B 107(36) (2003) 9669.

39. F. Roelofs and W. Vogelsberger, J. Phys. Chem. B 108(31) (2004) 11308.

40. S. Brunauer, P. H. Emmett, and E. Teller, J. Am. Chem. Soc. 60 (1938) 309.

41. S. Wolfram, Das Mathematica Buch. Addison-Wesley-Longman, Bonn-Paris (1997).

42. W. Hüttig and H. Ginsberg, Z. Anorg. Allg. Chem. 278 (1955) 93.

43. H. Ginsberg, W. Hüttig, and G. Strunk-Lichtenberg, Z. Anorg. Allg. Chem. 293 (1957) 33.

44. H. Ginsberg, W. Hüttig, and G. Strunk-Lichtenberg, Z. Anorg. Allg. Chem. 293 (1957) 204.

45. R.-S. Zhou and R. L. Snyder, Acta Crystallogr. B 47 (1991) 617.

46. Z. Wittmann, E. Kàntor, K. Bèlafi, L. Pèterfy, and L. P. Farkas, Talanta 39(12) (1992) 1583.

47. A. S. Ivanova, G. S. Litvak, G. N. Kryukova, S. V. Tsybulya, and E. A. Paukshtis, Kinet. Catal+ 41 (2000) 122.

48. G. Paglia, C. E. Buckley, A. L. Rohl, R. D. Hart, K. Winter, A. J. Studer, B. A. Hunter, and J. V. Hanna, Chem. Mater. 16 (2004) 220.

49. W. Vogelsberger, J. Schmidt, and F. Roelofs, Colloids Surfaces A (2008) 51.

50. I. G. Shenderovich, G. Buntkowsky, A. Schreiber, E. Gedat, S. Sharif, J. Albrecht, N. S. Golubev, G. H. Findenegg, and H. H. Limbach, J. Phys. Chem. B 107(43) (2003) 11942.

51. A. Vyalikh, T. Emmler, B. Grünberg, Y. Xu, I. G. Shenderovich, G. H. Findenegg, H. H. Limbach, and G. Buntkowsky, Z. Phys. Chem. 221(1) (2007) 155.

52. A. W. Adamson, Physical Chemistry of Surfaces. J. Wiley, New York-Singapore (1990).

53. D. F. Evans and H. Wennerström, The Colloidal Domain. VCH Publishers Inc., New York (1994). 